\title{
Reply to RE: Use of regression analysis in plant cell, tissue and organ culture experiments (44(3): 229-232)
}

\author{
J. C. Lorenzo • M. García-Borroto
}

Published online: 7 May 2009

(C) The Society for In Vitro Biology 2009

First of all, we would like to thank Dr. Jeffrey Adelberg for letting us know his opinion about our paper "Use of regression analysis in plant cell, tissue, and organ culture experiments" (44(3):229-232). Dr. Adelberg suggested two main re-analyses of the experimental data. We carried them out (Figures a, b).

Figure a shows a complex fourth degree polynomial function. We cannot find any biological explanation for it. What do the minimum values represent? According to this function, the optimum inositol concentration is $174.97 \mathrm{mg} \mathrm{l}^{-1}$. Why should we make such a conclusion from this sophisticated function?

A modified experimental analysis is shown in Figure b. Why should we discard two experimental treatments? One of them, the control $\left(0 \mathrm{mg} \mathrm{l}^{-1}\right.$ inositol $)$, is extremely important.

We therefore have to emphasize that, to our best understanding, Figure $\mathrm{c}$ shows the most adequate statistical strategy. It provides a clearer biological response for the original data (points in Figure a). The original data showed that $200 \mathrm{mg} \mathrm{l}^{-1}$ inositol was the best treatment to increase proteolytic activity. This concentration was an experimental treatment, not a prediction generated from a complicated mathematical function.
J. C. Lorenzo $(\bowtie) \cdot$ M. García-Borroto

Bioplant Centre, University of Ciego de Avila,

Ciego de Avila, Cuba

e-mail: jclorenzo@bioplantas.cu

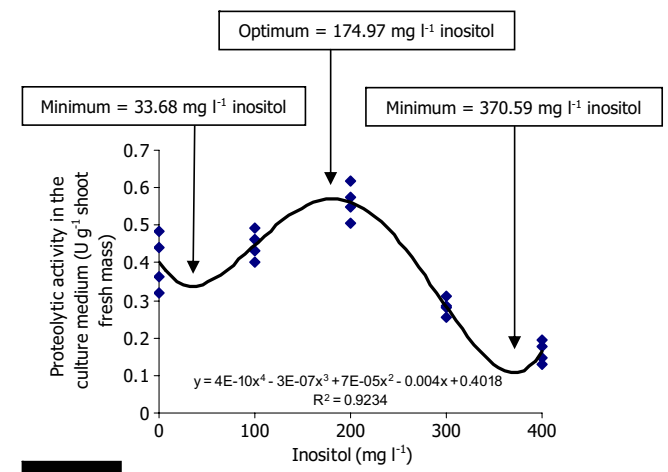

a

Fourth degree polynomial function suggested by Dr.

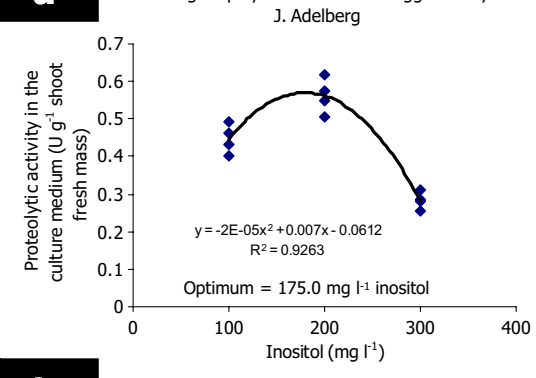

b

Second degree polynomial function suggested by D. J. Adelbergr

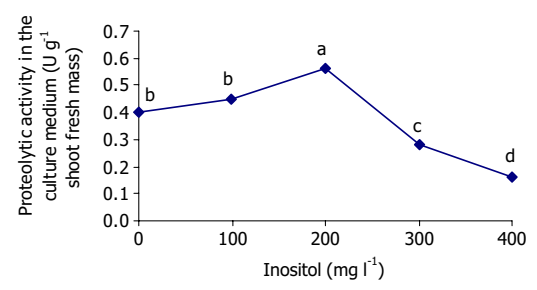

Media with the same letter are not statistically different (One-Way ANOVA, Tukey HSD, p greater

C Strategy recommended by Dr. Lorenzo and Dr. García-
Borroto 